\title{
Accelerated curing of PVAc adhesive on plasma-treated wood veneers
}

\author{
G. Avramidis · E. Nothnick • H. Militz • W. Viöl • \\ A. Wolkenhauer
}

Received: 20 November 2009 / Published online: 1 April 2010

(C) Springer-Verlag 2010

\begin{abstract}
In this study the effect of plasma treatment at atmospheric pressure of wood veneers on the curing behaviour of a PVAc adhesive was investigated. Time-dependent shear bond strength tests on untreated and plasma-treated maple (Acer pseudoplanatus), oak (Quercus sp.), beech (Fagus sylvatica) and teak (Tectona grandis) veneers were carried out. The results confirm that plasma treatment accelerated curing of the PVAc adhesive on the wood veneers.
\end{abstract}

\section{Introduction}

The curing of water-based coatings and adhesives such as poly vinyl acetate (PVAc) is influenced by the extraction of water. Depending on ambient conditions such as temperature, humidity, wettability and material absorptivity, these systems need a certain period of time to cure (Zeppenfeld and Grunwald 2005) and develop their full functionality or allow further industrial processing. These curing or drying times are often a limiting factor in industrial production and decrease productivity and output. Thus, there is a need to accelerate curing. An innovative method to achieve this objective is plasma treatment, which is currently the focus of

G. Avramidis · E. Nothnick · W. Viöl · A. Wolkenhauer ( $\square)$ University of Applied Sciences and Arts, Department of Sciences and Technology, Von-Ossietzky-Strasse 99, 37085 Göttingen, Germany

e-mail: wolkenhauer@hawk-hhg.de

\section{H. Militz}

Georg-August-University of Göttingen, Wood Biology and Wood Products, Büsgenweg 4, 37077 Göttingen, Germany

W. Viöl · A. Wolkenhauer

Laser-Laboratorium Göttingen e.V., Hans-Adolf-Krebs-Weg 1, 37077 Göttingen, Germany increasing research interest for wood modification (Vander Wielen et al. 2006; Evans et al. 2007; Custódio et al. 2008; Avramidis et al. 2009).

In previous studies, the effect of dielectric barrier discharge (DBD) treatment at atmospheric pressure on particle board and fibre board was investigated. It was shown that surface energy, especially the polar component, is significantly increased by plasma treatment, resulting in improved wettability of the surface (Wolkenhauer et al. 2007a). This led to faster water penetration and accelerated curing of a PVAc adhesive (Wolkenhauer et al. 2007b). Since plasma treatment increases also surface energy, polarity and wettability of wood surfaces (Topala and Dumitrascu 2007; Odrásková et al. 2008; Lecoq et al. 2008; Wolkenhauer et al. 2009), it is assumed that similar beneficial effects on the curing characteristics of PVAc adhesive can be obtained for plasma-treated wood veneers.

In the present study, the curing behaviour of a PVAc adhesive on plasma-treated veneers of maple, oak, beech and teak was investigated. The veneers were subjected to DBD treatment at atmospheric pressure. The curing behaviour of PVAc adhesive on untreated and plasma-treated wood veneers was measured using time-dependent shear bond strength tests.

\section{Experimental}

\subsection{Materials and methods}

Sliced veneers of maple (Acer pseudoplanatus), oak (Quercus sp.), beech (Fagus sylvatica) and teak (Tectona grandis) with a thickness of $0.6 \mathrm{~mm}$ were stored at $20^{\circ} \mathrm{C}$ and $65 \%$ $\mathrm{RH}$ before testing. A commercial PVAc adhesive (Ponal Super3, Henkel KGaA, Düsseldorf, Germany) was used for the 
shear bond strength tests. Two veneers $\left(20 \times 80 \mathrm{~mm}^{2}\right)$ were bonded with an overlap of $20 \mathrm{~mm}$ to achieve a glued area of $400 \mathrm{~mm}^{2}$ and pressed at $\sim 1 \mathrm{MPa}$. The pressing duration was varied and corresponds to the curing time. Shear tests were conducted using a tensile testing machine (Z010, Zwick GmbH \& Co. KG, Ulm, Germany) at a traverse speed of $20 \mathrm{~mm} / \mathrm{min}$, and ten specimens were tested for each curing time.

\subsection{Plasma set-up}

The veneer was positioned centrally between two insulated $\left(\mathrm{Al}_{2} \mathrm{O}_{3}, t=6 \mathrm{~mm}\right)$ electrodes $\left(300 \times 50 \times 50 \mathrm{~mm}^{3}\right)$ to obtain a discharge gap of $2 \mathrm{~mm}$ between the veneer and the electrode on both sides. An alternating high-voltage
( $\sim 35 \mathrm{kV}$ peak) pulse generator with a pulse duration of $2 \mu \mathrm{s}$ and a pulse repetition frequency of $17 \mathrm{kHz}$ was connected to one electrode, whereas the other electrode was grounded. In this unsealed set-up, ambient air at room temperature was blown through the discharge gaps with a velocity of $\sim 4 \mathrm{~m} / \mathrm{s}$. The treatment duration was $30 \mathrm{~s}$ for all experiments. Gas temperatures during plasma treatment were measured with a fibre-optic thermometer (FTI-10, FISO Technologies, Sainte-Foy, Canada) and did not exceed $50^{\circ} \mathrm{C}$.

\section{Results and discussion}

Curing of PVAc adhesives relies on the loss of water, whereas the setting rate on porous materials such as wood
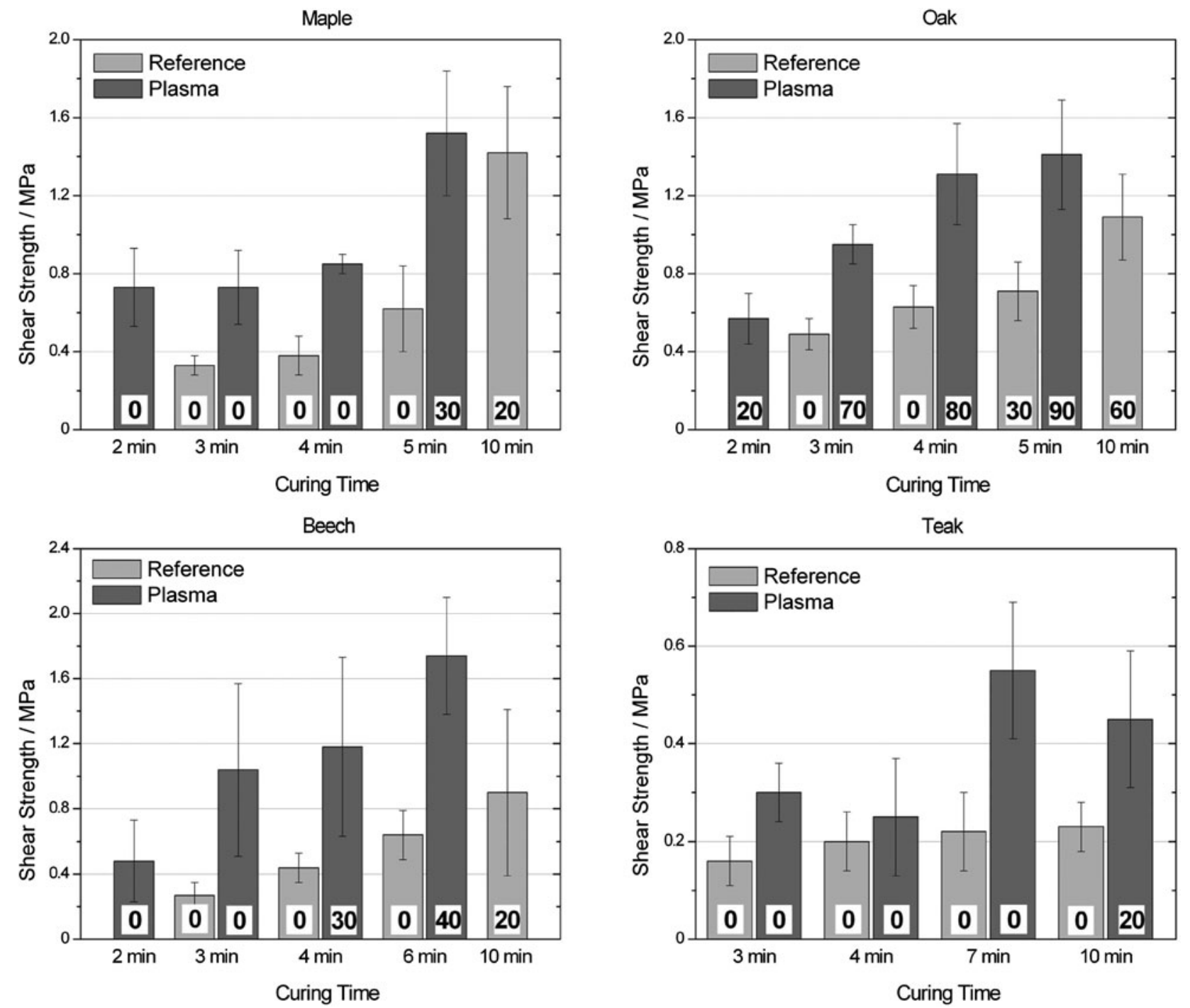

Fig. 1 Time-dependent shear bond strength of untreated and plasma-treated maple, oak, beech and teak veneers. Values at the bottom of the bars give the percentage of test specimens showing wood fracture

Abb. 1 Zeitabhängige Schertests unbehandelter und plasmabehandelter Ahorn-, Eichen-, Buchen- und Teak-Furniere. Die Zahlen am Fuß der Säulen zeigen den prozentualen Anteil an Proben, die Holzbruch aufwiesen 
is a direct function of the water absorptive capacity of the wood (Zeppenfeld and Grunwald 2005). Thus, changes in the water absorptive capacity of the wood affect the setting rate of a PVAc adhesive. Water absorption or penetration into the wood depends on the wood moisture content, absorptivity, temperature and surface energy characteristics of the wood and adhesive. In general the relatively low surface polarity of wood impedes wetting and prevents complete spreading of water (Nguyen and Johns 1979; Mantanis and Young 1997; Nussbaum 1993; Sakata et al. 1993). Thus, close and extensive contact is impeded so that water penetration into the wood is impaired. These processes can be improved by increasing the surface polarity of the wood, which can be achieved by plasma treatment. Plasma treatment increases the surface polarity by generating polar groups such as $\mathrm{C}-\mathrm{O}$ and $\mathrm{C}=\mathrm{O}$ (Uehara and Sakata 1990; Belgacem et al. 1995; Kogelschatz 2003; Klarhöfer et al. 2005) and thereby promotes wetting (Topala and Dumitrascu 2007; Odrásková et al. 2008; Lecoq et al. 2008). If plasma treatment positively affects water penetration into the wood by increasing its surface polarity, accelerated curing of PVAc adhesive and a faster increase in bond strength could result.

Figure 1 shows the results for time-dependent shear bond strength tests. Both untreated and plasma-treated veneers showed a continuous increase in shear bond strength with curing time, indicating the advancing setting process of the PVAc-adhesive by the permanent loss of water (Zeppenfeld and Grunwald 2005). For each curing time tested, all plasma-treated veneers had significantly higher shear bond strength than the untreated veneers, demonstrating accelerated curing of the PVAc adhesive after plasma treatment, which is mainly attributed to faster water penetration into the wood.

Similar results were obtained regarding the fracture behaviour. In Fig. 1, the percentage of specimens exhibiting wood fracture is also reported. In all cases the first occurrence of wood fracture was shifted towards shorter curing times for plasma-treated specimens.

As previously stated, shorter adhesive curing times would decrease processing times and increase production throughput and productivity in the plywood industry. Furthermore, from the results presented here it can be hypothesised that plasma pre-treatment might show similar beneficial effects using other water-based systems in applications such as bonding, painting and impregnation. Thus, the plasma technique could be a useful tool in industrial applications.

In general, the untreated veneers needed approximately double the curing time to reach the same shear bond strength as the plasma-treated veneers.

\section{Conclusion}

The results demonstrate that plasma treatment of wood veneers can considerably improve the curing characteristics of a PVAc adhesive. Curing times could be approximately halved using the plasma technique, which is mainly ascribed to faster water penetration into the wood. More research is needed to investigate the effect of plasma treatment on other water-based systems such as adhesives, coatings and impregnation agents and to evaluate its suitability in associated applications.

Acknowledgement Financial support from the Federal Ministry of Education and Research (BMBF, 1708X08) is gratefully acknowledged.

\section{References}

Avramidis G, Hauswald E, Lyapin A, Militz H, Viöl W, Wolkenhauer A (2009) Plasma treatment of wood and wood-based materials to generate hydrophilic or hydrophobic surface characteristics. Wood Mater Sci Eng 4(12):52-60

Belgacem MN, Czeremuszkin G, Sapieha S, Gandini A (1995) Surface, characterization of cellulose fibres by XPS and inverse gas chromatography. Cellulose 2:145-157

Custódio J, Broughton J, Cruz H, Winfield P (2008) Activation of timber surfaces by flame and corona treatments to improve adhesion. Int J Adhes Adhes 29(2):167-172

Evans PD, Ramos M, Senden T (2007) Modification of wood using a glow-discharge plasma derived from water. In: Hill CAS, Jones D, Militz H, Ormondroyd GA (eds) The third European conference on wood modification (ECWM3), Biocomposites Centre, University of Wales, Bangor, pp 123-132

Klarhöfer L, Frerichs M, Maus-Friedrichs M, Kempter V, Viöl W (2005) Investigation of pure and plasma treated spruce with surface analytical techniques. In: Militz H, Hill CAS (eds) The second European conference on wood modification (ECWM2). University of Göttingen, Göttingen, pp 339-345

Kogelschatz U (2003) Dielectric-barrier discharges: their history, discharge physics, and industrial applications. Plasma Chem Plasma Process 23:1-46

Lecoq E, Clément F, Panousis E, Loiseau JF, Held B, Castetbon A, Guimon C (2008) Pinus pinaster surface treatment realized in spatial and temporal afterglow DBD conditions. Eur Phys J Appl Phys 42:47-53

Mantanis GI, Young RA (1997) Wetting of wood. Wood Sci Technol 31:339-353

Nguyen T, Johns WE (1979) The effects of aging and extraction on the surface free energy of Douglas fir and redwood. Wood Sci Technol 13:29-40

Nussbaum RM (1993) Oxidative activation of wood surfaces by flame treatment. Wood Sci Technol 27:183-193

Odrásková M, Ráhel J, Zahoranová A, Tino R, Cernák M (2008) Plasma activation of wood surface by diffuse coplanar surface barrier discharge. Plasma Chem Plasma Process 28:203-211

Sakata I, Morita M, Tsuruta N, Morita K (1993) Activation of wood surfaces by corona treatment to improve adhesive bonding. J Appl Polym Sci 49:1251-1258

Topala I, Dumitrascu N (2007) Dynamics of the wetting process on dielectric barrier discharge (DBD)-treated wood surfaces. J Adhes Sci Technol 21:1089-1096 
Uehara T, Sakata I (1990) Effect of corona discharge treatment on cellulose prepared from beech wood. J Appl Polym Sci 41:16951706

Vander Wielen LC, Östenson M, Gatenholm P, Ragauskas AJ (2006) Surface modification of cellulosic fibers using dielectric-barrier discharge. Carbohydr Polym 65:179-184

Wolkenhauer A, Avramidis G, Cai Y, Militz H, Viöl W (2007a) Investigation of wood and timber surface modification by dielectric barrier discharge at atmospheric pressure. Plasma Process Polym 4:470-474
Wolkenhauer A, Avramidis G, Militz H, Viöl W (2007b) Wood modification by atmospheric pressure plasma treatment. In: Hill CAS, Jones D, Militz H, Ormondroyd GA (eds) The third European conference on wood modification (ECWM3). Biocomposites Centre, University of Wales, Bangor, pp 271-274

Wolkenhauer A, Avramidis G, Hauswald E, Militz H, Viöl W (2009) Sanding vs. plasma treatment of aged wood: a comparison with respect to surface energy. Int J Adhes Adhes 29:18-22

Zeppenfeld G, Grunwald D (2005) Klebstoffe in der Holz- und Möbelindustrie. DRW, Leinfelden-Echterdingen 